\title{
Effect of antioxidants on functional recovery after in vitro-induced ischemia and long-term potentiation recorded in the pyramidal layer of the CA1 area of rat hippocampus
}

\author{
Zdenka Gasparova, Veronika Stara and Svorad Stolc \\ Institute of Experimental Pharmacology and Toxicology, Slovak Academy of Sciences, Bratislava, Slovak Republic
}

\begin{abstract}
Ischemic stroke is one of the leading causes of cognitive impairment. Antioxidants may be beneficial in brain diseases in which oxidative stress can be assumed. The effect of two antioxidants, stobadine and its new derivative coded SMe1EC2, was studied on post-ischemic functional recovery in the hippocampus of young and 18-month-old rats. The synaptic transmission was apparently absent after 6-min hypoxia/hypoglycemia in both age groups. Re-oxygenation resulted in negligible functional recovery in untreated slices, yet the presence of pyridoindoles tested elicited improved recovery upon re-oxygenation. SMe1EC2 was found more effective in post-ischemic functional recovery and was further tested in the hippocampus of 15-month-old rats in long-term potentiation (LTP) experiments, a synaptic model of learning and memory mechanisms. In slices of aged rats, 3.5-min hypoxia/hypoglycemia resulted in depression of the LTP induction phase (immediately after high frequency stimulation) and this was prevented in the presence of SMe1EC2 $(3 \mu \mathrm{mol} / \mathrm{l})$. Upon "normoxia", marked amelioration of LTP was recorded in the presence of the antioxidant in about 1.5 order lower concentration. These results suggest a possible application of the pyridoindole in the management of brain ischemia and cognitive impairment.
\end{abstract}

Key words: Rat - Hippocampus - Ischemia — Long-term potentiation - Antioxidants

Abbreviations: ABTS, 2,2-azinobis-(3-ethyl-benzothiazoline-6-sulfonic acid); ACSF, artificial cerebrospinal fluid; AHT, acute head trauma; DPPH, 2,2-diphenyl-1-picrylhydrazyl; fEPSP, field excitatory postsynaptic potential; HFS, high frequency stimulation; LTP, long-term potentiation; PS, population spike; ROS, reactive oxygen species.

\section{Introduction}

Oxidative stress is one of the mechanisms frequently participating in acute and chronic neuronal damage (Chan 2001; Sugawara and Chan 2003; Fatokun et al. 2008; Saito et al.2005). The brain utilizes large quantities of oxygen and is sensitive to damage mediated by reactive oxygen species (ROS). The hippocampus is a brain region very sensitive to ischemic insults, manifested by loss of pyramidal cells in the CA1 area (Pulsinelli and Brierley 1979). Normal

Correspondence to: Zdenka Gasparova, Institute of Experimental Pharmacology and Toxicology, Slovak Academy of Sciences, Dubravska cesta 9, 84104 Bratislava, Slovak Republic

E-mail: zdenka.gasparova@savba.sk aging, brain ischemia, as well as chronic neurodegeneration resemble in several pathological features, including enhanced vulnerability of the CA1 area of the hippocampus (Larsson et al. 2001; Jackson et al. 2009). Neuronal tissue is equipped with protective enzymatic and non-enzymatic defensive antioxidative mechanisms, which offer a partial resistance to oxidative stress (Pellmar et al. 1992; Olney 1994). Disturbance of the balance between ROS production and the capacity of protective endogenous antioxidants results in tissue damage. Administration of antioxidants can improve histological, biochemical, neurobehavioral and electrophysiological outcomes after brain ischemia/ reperfusion or neurotrauma in animal models (Hall et al. 1992, 1996; Gasparova et al. 2006; Reiter et al. 2007, 2008). In human clinical practice, however, positive expe- 
rience with antioxidants used as neuroprotectants is rare. Reasons might be found in undesired side or toxic effects, thus new highly effective neuroprotective agents need to be developed. One of the extensively studied antioxidants is stobadine, ((-)-cis-2,8-dimethyl-2,3,4,4a,5,9b-hexahydro$1 \mathrm{H}$-pyrido[4,3-b]indole (Stolc et al. 1983; Benes and Stolc 1989), a pyridoindole drug derived from the $\gamma$-carboline antidepressant and neuroleptic drug carbidine (Barkov 1973). It was shown to exert multiple pharmacological effects including free radical scavenging, antioxidant, cardioprotective, $\alpha$-adrenolytic, cholinolytic, histaminolytic, hypotensive and membrane stabilizing action, along with other effects (Horakova and Stolc 1998; Juranek et al. 2010, 2012). Based on the antioxidant effect of stobadine, new more efficient substances were designed and synthetized in the Institute of Experimental Pharmacology and Toxicology, Slovak Academy of Sciences. In the stobadine molecule, sites responsible for antioxidant and antiradical properties were identified. By appropriate substitution, dozens of stobadine derivatives have been prepared. One of the new derivatives, substituted with methoxy-group on the aromatic cycle and ethoxycarbonyl-group substituted in position 2- of the piperidine nitrogen, is the compound 2-ethoxycarbonyl-8-methoxy-2,3,4,4a,5,9b-hexahydro$1 H$-pyrido-[4,3b]indolinium chloride, coded SMe1EC2. There is evidence of successful modification of the parental compound resulting in remarkable enhancement of its capacity to protect against tissue injury associated with increased production of ROS (Juranek et al. 2010; Stolc et al. 2010). Modification in the stobadine structure resulted in remarkable enhancement of its capacity to inhibit lipoperoxidation and oxidative injury of creatine phosphokinase in rat brain homogenates exposed to $\mathrm{Fe}^{2+} /$ ascorbate system. Antiradical efficacy was confirmed in 2,2-azinobis (3-ethyl-benzothiazoline-6-sulfonic acid) (ABTS) and 2,2-diphenyl-1-picrylhydrazyl (DPPH) assays and strong elimination of hydroxyl radicals was observed by electron spin resonance method. Compared to stobadine, decreased acute toxicity was observed, which was linked to successful elimination of $\alpha$-adrenolytic activity and thus elimination of hypotensive effect was obtained. Improvement in neurologic deficit, occurring mostly one hour after acute head trauma (AHT), was observed after single i.v. administration of SMe1EC2 immediately after AHT in mice (Stolc et al. 2011). Further, a prenatal developmental teratological study of SMe1EC2 showed its low toxicity with no embryotoxic and teratogenic effects on developing rats and no signs of maternal toxicity (Ujhazy et al. 2008). This new pyridoindole with antioxidant properties might find use as a protective agent in acute or chronic diseases in which oxidative stress can be assumed.

Ischemic stroke is one of the leading causes of marked cognitive impairment, especially in elderly humans (Cum- ming et al. 2013). One third of stroke patients develop dementia (Zhu et al. 1998). Long-term potentiation (LTP) is used as an experimental model for studying synaptic events during learning and memory (Bliss and Collingridge 1993; Morris 2003; Lynch 2004). Recently, we reported an unfavorable effect of transient hypoxia with hypoglycemia on LTP in the young rat hippocampus (Gasparova et al. 2008). However, the mechanisms of progressive cognitive decline following brain ischemia are not yet understood. Antioxidants could find use as protective agents in acute or chronic brain diseases in which oxidative stress can be assumed. The main purpose of the present work was to study effects of antioxidants on two pathological conditions, i) ischemia, and ii) age-induced memory deficit. Ischemic conditions were induced by hypoxia/hypoglycemia followed by re-oxygenation/normoglycemia of rat hippocampal slices. The effect of the new prospective compound, the pyridoindole SMe1EC2, was studied on post-ischemic functional recovery in the hippocampus of young and old rats. Its effect was compared with the effect of its parental compound stobadine. Electrically evoked responses were monitored in the CA3-CA1 synapse during ischemic and post-ischemic conditions in vitro. Synaptic plasticity was determined by LTP measurements. The induction and maintenance of LTP was monitored under "normoxia" or after transient in vitro-induced ischemia in rat hippocampal slices in the presence or absence of the antioxidant SMe1EC2 in aged rats. The main question was whether the new antioxidant tested could exert a neuroprotective effect on neuronal function in ischemia and even serve as protection of synaptic memory mechanism.

\section{Materials and Methods}

\section{Animals}

Male Wistar rats were used from the breeding station Dobra Voda (Slovak Republic, reg. No. SK CH 24011). Rats had free access to water and food pellets and were kept on $12 \mathrm{~h} / 12 \mathrm{~h}$ light/dark cycle. The effect of two antioxidants was tested during and after in vitro-induced ischemia in two age groups of male Wistar rats: young (2.5-month-old, $N=20$, weight 220-240 g) and aged rats (18-month-old, $N=14$, weight $400-450 \mathrm{~g})$. The effect of the new pyridoindole derivative SMe1EC2 on LTP was measured in hippocampal slices of aged 15-month-old Wistar rats $(N=26$, weight 350-450 g). All procedures involving animals were performed in compliance with the Principles of Laboratory Animal Care issued by the Ethical Committee of the Institute of Experimental Pharmacology and Toxicology, Slovak Academy of Sciences and by the State Veterinary and Food Administration of Slovakia. 
Preparation of hippocampal slices and electrophysiological measurement

Hippocampal slices were prepared by a conventional technique. Slices $(400 \mu \mathrm{m})$ cut by tissue chopper (McIlwain Tissue Chopper, Stoelting, USA) were positioned on a supporting nylon mesh separating liquid and gas phases in the incubation chamber at $34^{\circ} \mathrm{C}$. The aqueous phase consisted of artificial cerebrospinal fluid (ACSF) composed of (in mmol/l): $\mathrm{NaCl} 124, \mathrm{KCl} 3.3, \mathrm{KH}_{2} \mathrm{PO}_{4}$ 1.25, $\mathrm{MgSO}_{4} 2.4, \mathrm{CaCl}_{2} 2.5, \mathrm{NaHCO}_{3} 26$, glucose 10 and saturated with $95 \% \mathrm{O}_{2}+5 \% \mathrm{CO}_{2}$, at $\mathrm{pH} 7.4$ and the gas phase consisted of $95 \% \mathrm{O}_{2}+5 \% \mathrm{CO}_{2}$. Both phases were continuously flowing through the incubation and experimental chambers. Bipolar wire electrodes were used to stimulate extracellularly Schäffer collaterals evoking trans-synaptically activity in the CA1area. Synaptic transmission was recorded in the stratum pyramidale of the CA1 region by a glass microelectrode (3-5 M $\Omega$ ) filled with ACSF. Recordings were amplified, visualized on the oscilloscope (Tektronix 2230, Tectronics, Inc., USA), digitalized by the DigiData 1322A (Molecular Devices, USA) with sampling rate of $10 \mathrm{kHz}$. Synaptic waveforms were stored on personal computer for further analysis by the software AxoScope 10.2 and 10.3.

\section{Model of in vitro induced ischemia: glucose and oxygen deprivation and effects of antioxidants on synaptic responses of ischemic tissue}

Schäffer collaterals were electrically stimulated (stimulus duration of $0.1 \mathrm{~ms}$; stimulus frequency of $0.02 \mathrm{~Hz}$; stimulus intensity within 5-30 V) and population spike (PS) amplitude induced by supra-maximal stimulation was considered to be a measure of efficiency of synaptic transmission. At the onset of individual recording, maximal PS amplitude was checked by two cursors on the oscilloscope screen and then the stimulus intensity eliciting the maximal PS amplitude was increased by about $5-10 \%$ to measure supra-maximal response. The CA3-CA1 synapse was stimulated and the baseline response was monitored minimally over 10-15 min. Supra-maximal stimulation of the CA3-CA1 synapse elicited PS with an amplitude which varied from 4 to $14 \mathrm{mV}$ in individual slices, thus the mean PS amplitude recorded during 10 min before onset of hypoxia/hypoglycemia was considered the response of $100 \%$ for a given slice. After replacing the gas mixture with $95 \% \mathrm{O}_{2}+5 \% \mathrm{CO}_{2}$ by the gas mixture with $95 \% \mathrm{~N}_{2}+5 \%$ $\mathrm{CO}_{2}$, along with superfusion of the slices with ACSF with diminishing glucose from the concentration of 10 to 4 $\mathrm{mmol} / \mathrm{l}$ and equilibrated with the oxygen-free gas mixture, synaptic transmission was quickly abolished. Functional recovery after hypoxia/hypoglycemia was monitored dur- ing re-oxygenation/normoglycemia and PS amplitude was measured in a later analysis. Recovery of functional response at the end of 20-min re-oxygenation was expressed as percentage of the mean PS amplitude recorded during a 10-min period before onset of hypoxia/hypoglycemia. The compound tested was present in the superfusing medium $30 \mathrm{~min}$ before hypoxia and throughout the whole experiment, i.e. during 6-min hypoxia/hypoglycemia and during 20-min re-oxygenation/normoglycemia of hippocampal slices.

\section{Measurement of LTP at the CA3-CA1 synapse under "normoxia"}

Schäffer collaterals were stimulated with the stimulus frequency of $0.05 \mathrm{~Hz}$ and the stimulus duration of $0.1 \mathrm{~ms}$. The field excitatory postsynaptic potential (fEPSP) was recorded in the stratum pyramidale of the CA1 area in the hippocampus of aged rats $(N=10)$. At the onset of LTP experiments, the stimulus intensity was reduced to obtain about $50 \%$ of fEPSP amplitude in which PS generation amplitude started to be detected. Slices were stimulated and stabilized for about $15 \mathrm{~min}$. The drug tested was applied $30 \mathrm{~min}$ before high-frequency stimulation (HFS) of the CA3-CA1 synapse and it was present throughout the rest of the experiment. LTP was induced by HFS of a single $100-\mathrm{Hz}$ train with 1 -s train duration. After HFS, the baseline stimulation recording $(0.05 \mathrm{~Hz})$ continued for at least $60 \mathrm{~min}$.

\section{Measurement of LTP at the CA3-CA1 synapse exposed to transient ischemia}

The drug tested was applied $30 \mathrm{~min}$ before transient $3.5-\mathrm{min}$ hypoxia/hypoglycemia followed by 20 -min reoxygenation and then HFS of a single 100-Hz train with 1-s train duration was applied. After HFS, the baseline stimulation recording continued for at least $60 \mathrm{~min}$, thus recording from each slice lasted more than $120 \mathrm{~min}$. The drug tested was present throughout the whole experiment.

\section{Data analysis}

The data were statistically evaluated using the InStat software ver. 2.05 (GraphPad Software).

Data were expressed as means \pm S.E.M. One-way ANOVA was used to evaluate: a) the difference among all experimental groups (Tukey-Kramer comparison test, Student-Newman-Keuls multiple comparison test), b) the difference compared to controls (Dunnett multiple comparisons test). The difference between two groups was evaluated by the Student $t$-test. The value $p$ below 0.05 was considered a statistically significant difference. 


\section{Results}

Concentration-response relationship of stobadine and SMe1EC2 effect on functional recovery after in vitro induced ischemia in the hippocampus of young and old rats

Synaptic transmission in the CA3-CA1 synapse in the rat hippocampus is highly sensitive to lack of oxygen and glucose. The magnitude of baseline response recorded during the stabilization period (Fig. 1A) was rapidly reduced during in vitro-induced ischemia. Disappearance of electrically evoked field action potential was observed at the end of 6-min hypoxia/hypoglycemia in the hippocampus of young as well as old rats (Fig. 1B). Recovery of neurotransmission recorded in the stratum pyramidale of the CA1 area was monitored during 20-min re-oxygenation/normoglycemia (Fig. 1C). Hypoxia/hypoglycemia followed by re-oxygenation/normoglycemia resulted in negligible neurotransmission recovery with PS amplitude of $8.4 \pm 4.1 \%$ in untreated ischemic slices of 2.5-month-old rats $(N=20$ rats, $n=20$ slices) as well as of $14.9 \pm 7.8 \%$ in 18 -month-old rats $(N=14$ rats, $n=14$ slices) compared to their average PS amplitude before onset of in vitro induced ischemia (Fig. 2). Presence of the antioxidant tested for $30 \mathrm{~min}$ before onset of hypoxia/ hypoglycemia and throughout the experiment resulted in improved functional recovery upon re-oxygenation compared to untreated ischemic slices in both age groups. In young rats, SMe1EC2 elicited significant improvement of PS recovery at the end of 20-min re-oxygenation by each of the

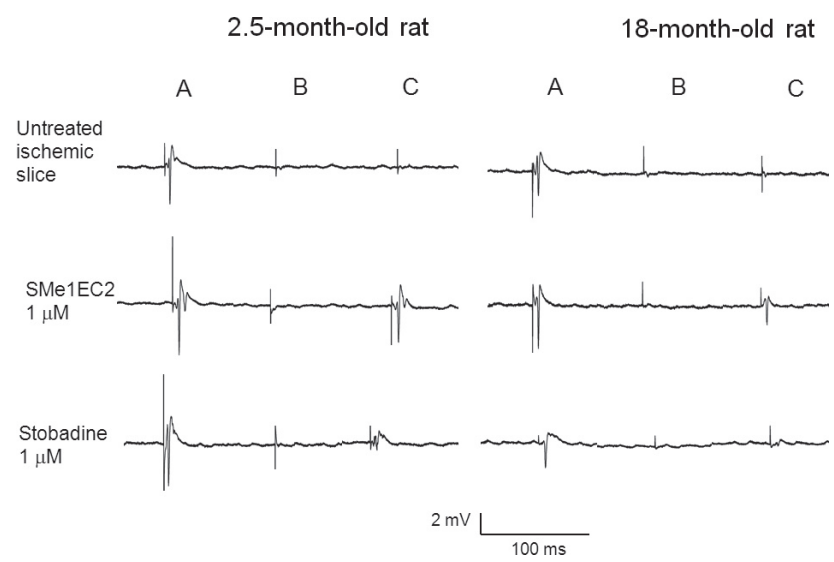

Figure 1. Effect of SMe1EC2 and stobadine on functional recovery after hypoxia/hypoglycemia measured at the CA3-CA1 synapse at the pyramidal layer of the rat hippocampus. The compounds tested were present in the superfusing medium 30 min before hypoxia/hypoglycemia and throughout the experiment. Representative recordings right before onset of hypoxia (A), at the end of 6-min hypoxia (B), and at the end of 20-min re-oxygenation (C) of hippocampal slices of 2.5-month-old and 18-month-old rats. Calibration is inserted. four concentrations tested and stobadine elicited significant improvement by the two highest concentrations tested, compared to low recovery in untreated ischemic slices (ANOVA, Dunnett Multiple Comparisons test, $p<0.05$ ) (Fig. 2). In the young rat hippocampus, both antioxidants exerted a lowered effect in the concentration of $10 \mu \mathrm{mol} / 1$ compared to the concentration of $3 \mu \mathrm{mol} / \mathrm{l}$, but this decrease in effectiveness was not significant (unpaired $t$-test). However, a trend to pro-oxidative effect might be present in the action of both antioxidants tested in high concentrations on the young rat hippocampus. By comparing the neuroprotective effect elicited by the same concentration of the two compounds tested, SMe1EC2 was found to be more effective than stobadine in the concentration of $1 \mu \mathrm{mol} / \mathrm{l}$ in the hippocampus of 18-month-old rats (Student $t$-test, $p=0.0259$ ) (Fig. 2; empty circle $v s$. empty square). In young rats, SMe1EC2 seems to be more effective than the parental stobadine in the concentrations $0.1,1$ and $3 \mu \mathrm{mol} / \mathrm{l}$ (not quite significant; Student $t$-test). Further, SMe1EC2 exerted a more protective effect in the concentration of $1 \mu \mathrm{mol} / \mathrm{l}$ in the young rat hippocampus, compared to the effect of the same concentration of stobadine in the old rat hippocampus (Tukey-Kramer multiple comparisons test, $p<0.05$ ) (Fig. 2; full circle $v s$. empty square).

\section{Effect of SMe1EC2 on LTP in the hippocampus of old rats}

Since ischemic stroke is one of the leading causes of marked cognitive impairment, the observed effect of antioxidantmediated improvement of post-ischemic functional recovery in the CA3-CA1 synapse of the rat hippocampus prompted us to study the putative beneficial effect of the antioxidant on LTP, which is regarded a cellular model of learning and memory. The compound SMe1EC2 was tested on LTP, as it was found to be more effective than stobadine under ischemic conditions in vitro. Since the main risk factor of cognitive impairment is aging, we performed these experiments on old rats ( $N=26$ rats, $n=69$ slices). The mean fEPSP amplitudes immediately after HFS and 60 min after HFS were evaluated and considered the measure of the LTP induction and maintenance, respectively. Augmentation of synaptic neurotransmission immediately after HFS $(100 \mathrm{~Hz}, 1 \mathrm{~s})$ represented $185 \pm 12 \%$ in the CA3-CA1 synapse of control untreated hippocampal slices $(n=8)$ of 15 -month-old rats. LTP was maintained for at least one hour after HFS with the amplitude of $155 \pm 19 \%$ in the $60^{\text {th }}$ min after HFS. Transient 3.5 -min ischemia resulted in significant reduction of the induction phase of LTP (Fig. 3A,B) (Student-NewmanKeuls multiple comparison test; $p<0.05 ; n=8$ ) compared to control LTP. This reduction was prevented in slices treated with SMe1EC2 in the concentration of $3 \mu \mathrm{mol} / \mathrm{l}(n=8)$ (Fig. $3 \mathrm{~A}, \mathrm{~B})$. Maintenance of LTP in the $60^{\text {th }}$ min after HFS did not significantly differ in the mentioned experimental groups of 
hippocampal slices, however the trend of changes was similar as in the induction phase (Fig. 3A,C). A representative recording is illustrated in Fig. 3D.

Effect of SMe1EC2 was tested on LTP under normal conditions ("normoxia") as well (Fig. 4). In "normoxic" slices treated with SMe1EC2, the lowest concentration $(0.1 \mu \mathrm{mol} / \mathrm{l}$; $n=10)$ of the compound tested elicited marked augmentation of synaptic transmission immediately after HFS (269 $\pm 29 \%$ ) compared to the control slices. This increase was maintained for at least one hour after HFS with a mild decline of the amplitude to $227 \pm 21 \%$ in the $60^{\text {th }}$ min after HFS (Fig. 4A,B,C). A representative recording is illustrated in Fig. 4D.

\section{Discussion}

The purpose of pharmacological research is to develop drugs with potent neuroprotective effect and to diminish the oxidative stress-induced injury, e.g. in stroke. During ischemia, reduction of synaptic transmission was demonstrated in hippocampal slices (Canhao et al. 1994; Latini et al. 1999; Gasparova et al. 2006, 2008). The effect of ischemia on neurotransmission and evidence of long-lasting synaptic failure were reported as a cause of persistent signs in patients with cerebral ischemia (Hofmeijer and van Putten 2012). Several mechanisms underlie the block of synaptic function in neurons during ischemic insults. Energy failure, disruption of ionic homeostasis, increase of intracellular $\mathrm{Ca}^{2+}$ concentration, accumulation of glutamate leading to excitotoxicity, increased generation of reactive oxygen and nitrogen species, etc. contribute to neuronal injury (Brouns and De Deyn 2009). Excitatory amino acid-receptor antagonists, $\mathrm{Ca}^{2+}$ channel blockers, voltage-dependent $\mathrm{Na}^{+}$channel blockers or antioxidants could provide neuroprotection under ischemia (Candelario-Jalil 2009). Increase of ROS production that occurs during reperfusion has been documented to be involved in ischemic neuronal degeneration (Negishi et al. 2001; Sanderson et al. 2013). As the capacity of endogenous antioxidative systems is limited, treatment of neuronal tissue with antioxidants may help to protect the neuronal tissue against ROS (Zhang et al. 2009). In the present work, apparently increased recovery of neuronal function after 6-min hypoxia/hypoglycemia in stobadineand SMe1EC2-treated hippocampal slices of young as well as old rats was observed, contrary to almost irreversibly impaired untreated ischemic slices. Improved recovery could be thus considered a neuroprotective action. The more powerful protective effect of SMe1EC2 may be explained by its higher anti-lipoperoxidation activity compared to stobadine (Stolc et al. 2006). The possibility of disruption of permeability and ion homeostasis is thus lowered due to antioxidant action in the neuronal membrane. Further, an inhibitory effect of SMe1EC2 on increased protein carbonyl formation mediated by the $\mathrm{Fe}^{2+}$ /ascorbic acid system, conditions involving oxidative stress, was reported (Gasparova et al. 2010). SMe1EC2 might protect neurons from damage of cell proteins and membrane lipids during ischemic insult. Antioxidants with different structure, e.g. the neurohormone melatonin, trolox, 21-aminosteroid U-74389G (Vlkolinsky and Stolc, 1999) and a melatonin analog 2,3-dihydromelatonin (Gasparova et al. 2006), exerted similar protective activity on synaptic transmission recovery in re-oxygenation of the rat hippocampus.

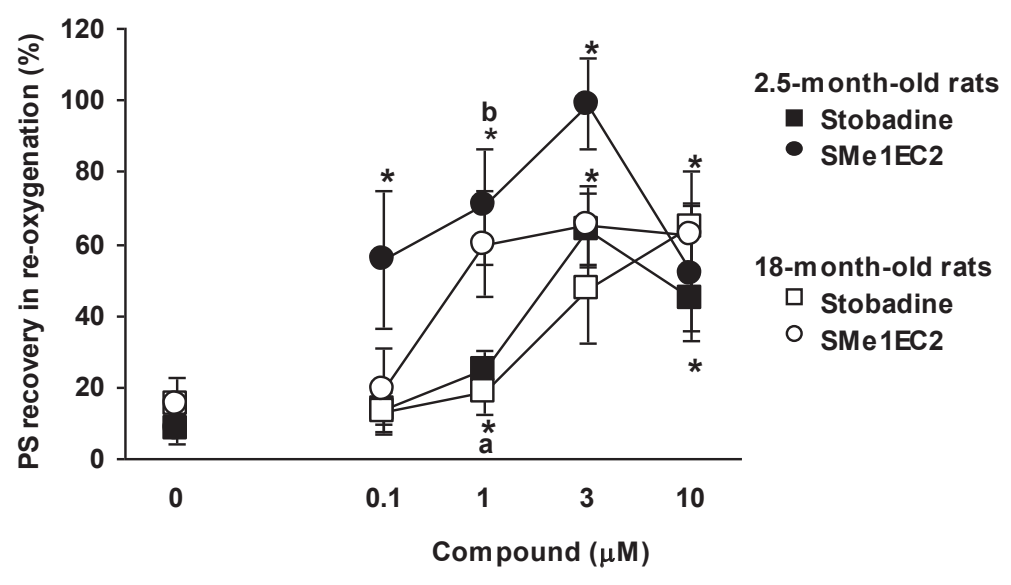
than stobadine in the concentration of $1 \mu \mathrm{mol} / \mathrm{l}$ in hippocampus of 18 -month-old rats (Student t-test, ${ }^{\mathrm{a}} p=0.0259$; empty circle $v$ s. empty square). SMe1EC2 exerted a more protective effect in the concentration of $1 \mu \mathrm{mol} / \mathrm{l}$ in young rat hippocampus compared to the effect of the same concentration of stobadine in the old rat hippocampus (One-way ANOVA, Tukey-Kramer multiple comparisons test, ${ }^{\mathrm{b}} p<0.05$; full circle $v s$. empty square).

Figure 2. Effect of SMe1EC2 and stobadine on the recovery of population spike (PS) amplitude after hypoxia/hypoglycemia at the end of 20-min re-oxygenation/normoglycemia recorded at the CA3-CA1 synapse in the hippocampus of 2.5 -month-old $(N=$ $20)$ and 18 -month-old rats $(N=14)$. The values are means \pm S.E.M. Each mean value represents measurements from 6 to 11 hippocampal slices. The injury resulted in irreversible transmission failure in most untreated slices. The compounds tested were present in the superfusing medium $30 \mathrm{~min}$ before 6-min hypoxia/hypoglycemia and throughout the experiment. Significant difference of PS recovery in treated slices compared to untreated ischemic slices ${ }^{*} p<0.05$ (One-way ANOVA, Dunnett multiple comparisons test). SMe1EC2 was more effective 
A

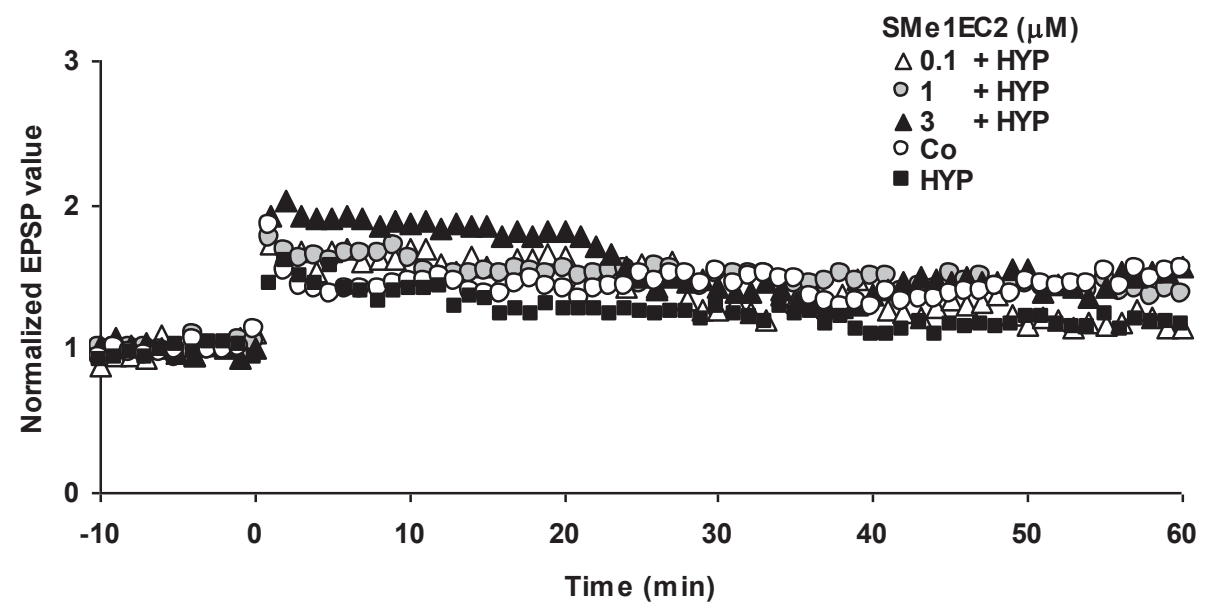

B

Immediately after HFS

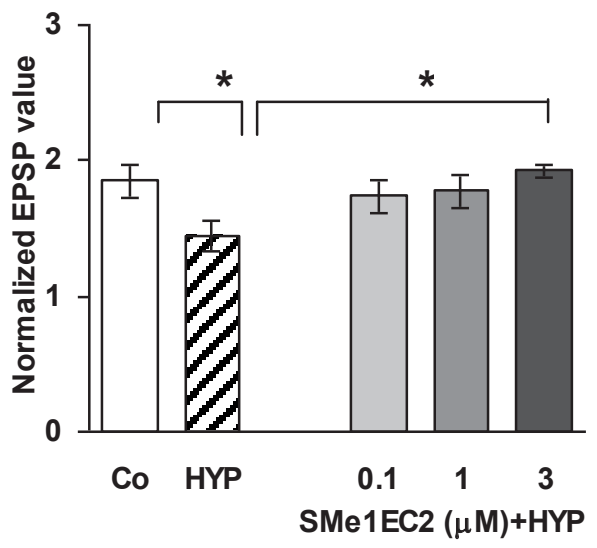

D

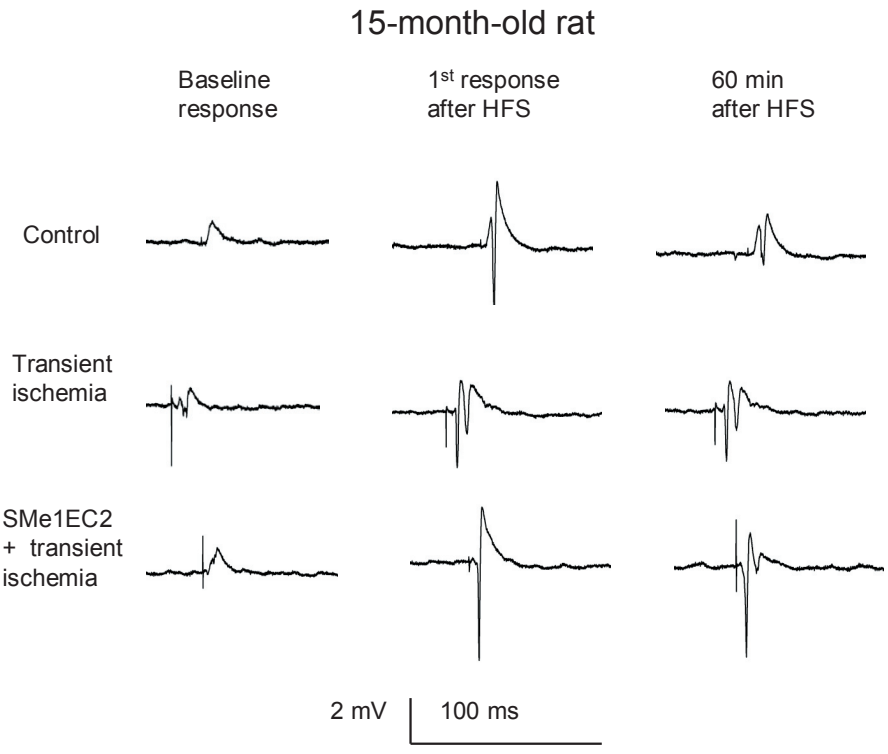

C

60 min after HFS

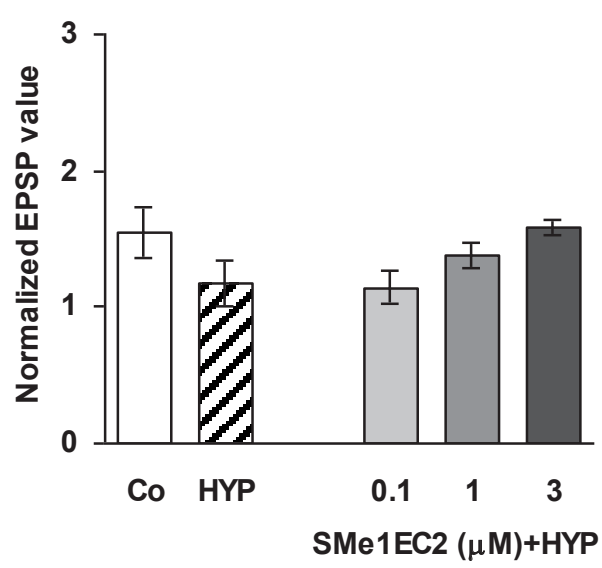

Figure 3. Effect of SMe1EC2 on long term potentiation (LTP) of the excitatory postsynaptic potential (EPSP) amplitude in the CA3-CA1 synapse of the hippocampus of 15-month-old rats $(N=16$ rats, $n=38$ slices) exposed to transient ischemic conditions. Values are means \pm S.E.M. except $(3 \mathrm{~A})$ where standard errors are not included for reason of lucidity; they ranged $3-8 \%$ of their mean value. Each mean value represents measurements from 5 to 9 hippocampal slices. High frequency stimulation (HFS; $100 \mathrm{~Hz}, 1 \mathrm{~s}$ ) was applied at time zero, after 10 min stabilization period (A). Reduction of induction phase of LTP was observed in slices exposed to transient 3.5-min hypoxia/hypoglycemia (HYP) compared to control (Co) LTP (A, B), while maintenance of LTP during 60-min registration after HFS was not significantly changed $(A, C)$. Effect of SMe1EC2 was tested in slices exposed to HYP in the concentrations of $0.1,1$ and $3 \mu \mathrm{mol} / 1(0.1+\mathrm{HYP}, 1+\mathrm{HYP}$ and $3+\mathrm{HYP}$ ). Elimination of reduction of induction phase of LTP was obtained in the presence of the pyridoindole in the concentration of $3 \mu \mathrm{mol} / \mathrm{l}$, ${ }^{*} p<0.05$ (One-way ANOVA, Student-Newman-Keuls multiple comparisons test). Representative recordings are shown (D). Calibration is inserted. 
A

SMe1EC2 ( $\mu \mathrm{M})$

$\square 0.1$

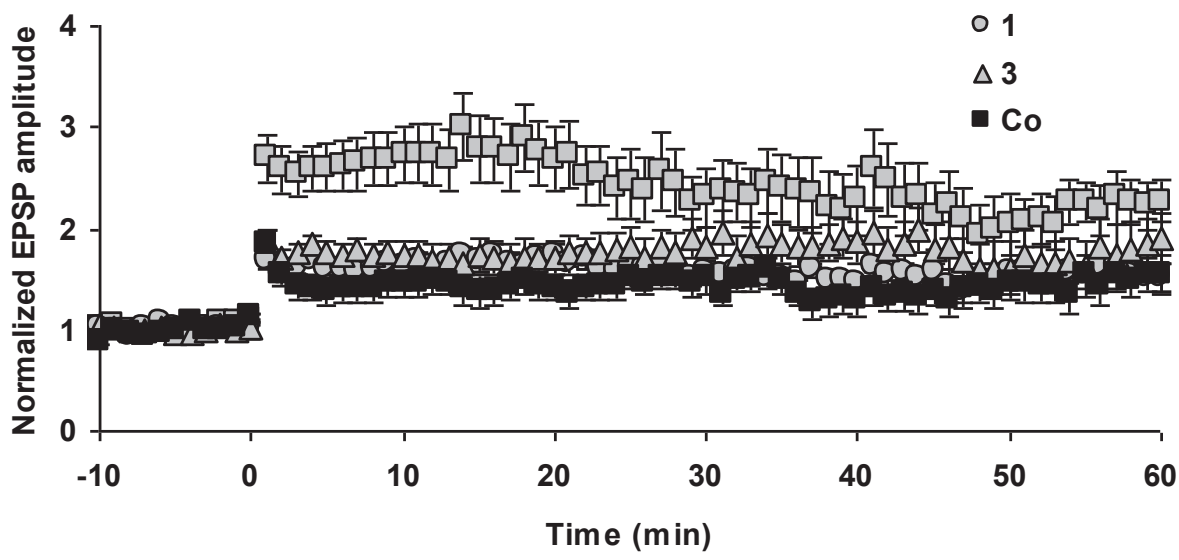

B

C
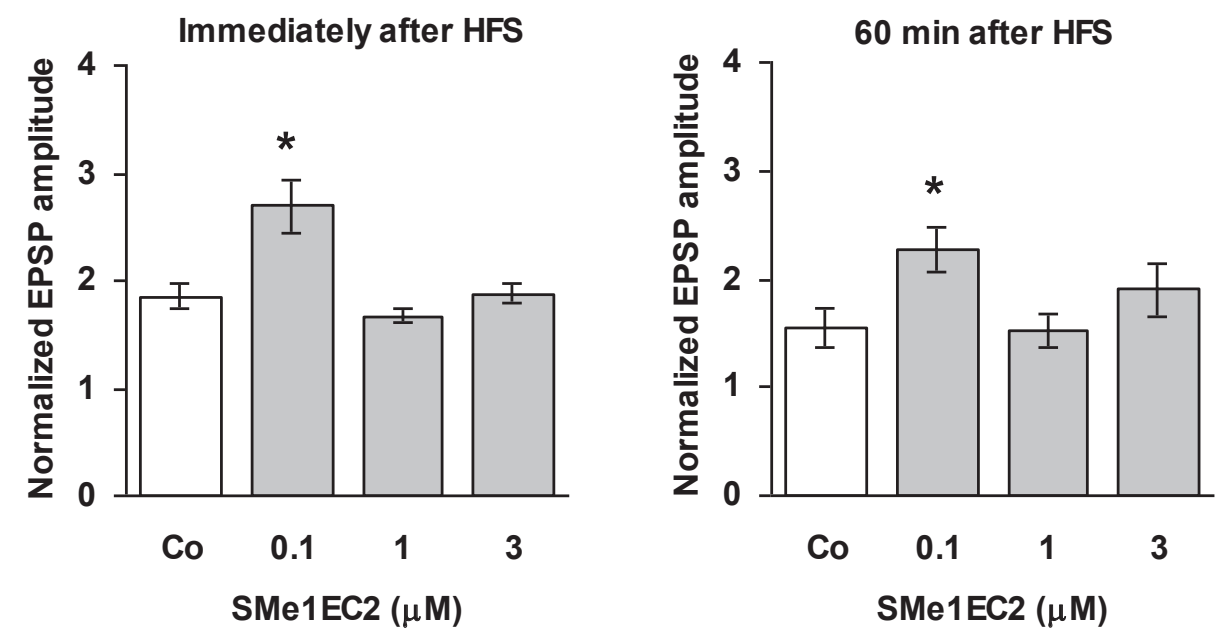

D

15-month-old rat

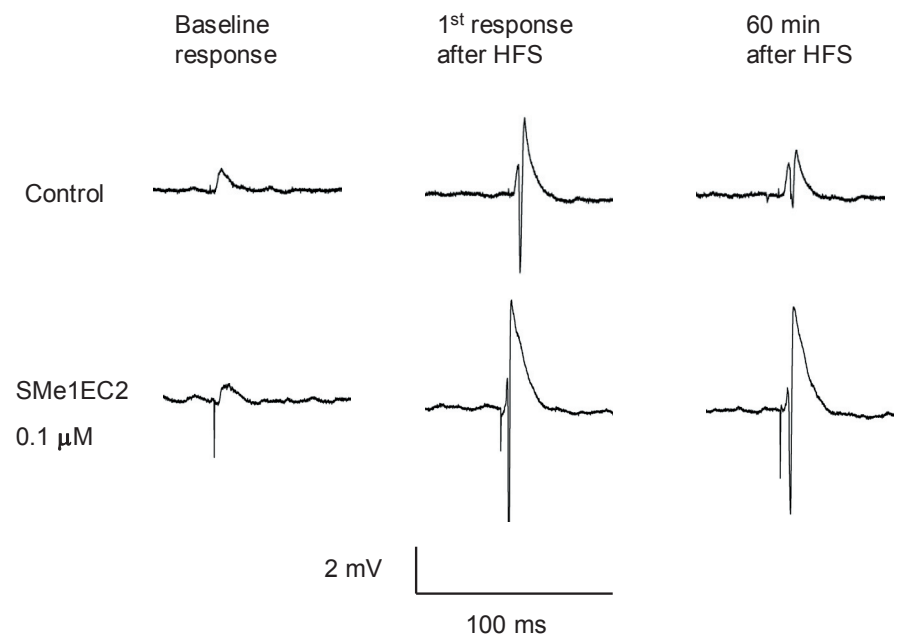

Figure 4. Effect of SMe1EC2 on long term potentiation (LTP) of the excitatory postsynaptic potential (EPSP) amplitude in the CA3-CA1 synapse of the hippocampus of 15-month-old rats ( $N=10$ rats, $n=31$ slices) under "normoxia". Values are means \pm S.E.M. High frequency stimulation (HFS; $100 \mathrm{~Hz}$, $1 \mathrm{~s})$ was applied at time zero, after $10 \mathrm{~min}$ stabilization period. Effect of SMe1EC2 was tested in slices in the concentrations of $0.1,1$ and $3 \mu \mathrm{mol} / 1(0.1,1,3)$. The lowest concentration tested $(0.1 \mu \mathrm{mol} / \mathrm{l})$ elicited significant augmentation of induction (A, B) and maintenance of LTP during $60 \mathrm{~min}$ after HFS (A, C) compared to control (Co) LTP values in untreated hippocampal slices, ${ }^{*} p<0.05$ (One-way ANOVA, Dunnett multiple comparisons test). Representative responses recorded in the pyramidal layer of untreated and treated hippocampal slices (D). Calibration is inserted. 
Recent literary data have pointed out that ROS are not only neurotoxic but they function as small messenger molecules in normal neuronal processes. HFS-induced LTP is dependent on the activation of NMDA subtype of glutamate receptors (Collingridge et al. 1983), influx of $\mathrm{Ca}^{2+}$ into postsynaptic pyramidal neurons (Lynch et al. 1983; Malenka et al. 1988) and production of small messenger molecules that along with $\mathrm{Ca}^{2+}$ trigger the activation of a number of protein kinase signaling cascades (Robertson et al. 1996; Malenka and Nicoll 1999). One of the small messenger molecules produced after HFS stimulation, which appears to be critical for LTP, is the superoxide radical. Scavengers of superoxide blocked LTP (Klann 1998; Klann et al. 1998). Further, a brief incubation of hippocampal slices with the superoxide-generating system xanthine/xanthine oxidase produced a long-lasting potentiation of synaptic transmission in the area CA1 (Knapp and Klann, 2002a, 2002b). Hippocampal slices from transgenic mice which over-express either cytoplasmic superoxide dismutase or extracellular superoxide dismutase exhibited impaired LTP (Gahtan et al. 1998; Thiels et al. 2000). Consistently with the idea about the essential role of ROS in synaptic plasticity, incubation of hippocampal slices with the antioxidant SMe1EC2 under "normoxia" produced reduction of HFS-induced LTP of synaptic transmission in the CA3-CA1 synapse of the young rat hippocampus (Gasparova et al. 2011). Impairment of synaptic plasticity was observed with the antioxidant melatonin, which impaired LTP in the dentate gyrus area of the adult rat hippocampus and induced learning and memory deficit in control rats (Cao et al. 2009). Administration of a-lipoic acid to control offspring rats resulted in a significant impairment of LTP amplitude (Wang et al. 2008).

In aged animals, the situation is probably different. Age-related decreases were found in the concentration of ascorbic acid, $a$-tocopherol, and arachidonic acid in the hippocampus (O'Donnell and Lynch 1998). These authors also observed increase in lipid peroxidation. Increased basal level of protein carbonyl groups was found in the cortex of aged rats (Gasparova et al. 2010). It has been suggested that age-related changes in redox status, ROS over-production and decreased defense mechanisms in the hippocampus may result in oxidative stress, which could be deleterious to LTP in the aged animal. Contrary to young animals, in aged ones dietary supplementation with $\alpha$-tocopherol, omega- 3 fatty acids and $\alpha$-lipoic acid reversed age-related impairment of LTP in the hippocampus (Murray and Lynch 1998; McGahon et al. 1999a, 1999b). In accordance with the above mentioned studies, the prospective pyridoindole antioxidant SMe1EC2 improved LTP in the CA3-CA1 synapse in the hippocampus of aged Wistar rats. Different redox status has been suggested to play an important role in the final effect of antioxidants in control or ischemic tissue of aged or young individuals. Aging is associated with decreased synaptic plasticity and a reduced ability to induce LTP (Lynch 1998). Hypothetically, the neuroprotective action of low concentrations of antioxidants in aged nervous tissue may be based on their effect in helping to approach the redox status to that in nervous tissue of young individuals. In slices subjected to transient in vitroinduced ischemia, reduction of the induction phase of LTP was prevented in the presence of the pyridoindole tested in such a concentration which elicited the best functional recovery during re-oxygenation of ischemic slices.

\section{Conclusion}

In conclusion, the pyridoindole antioxidants SMe1EC2 and stobadine elicited function recovery after in vitro-induced ischemia upon re-oxygenation of the hippocampus of young and old rats. In ischemic hippocampal slices of old rats, depression of the induction phase of LTP was eliminated by SMe1EC2. Under "normoxia", induction and maintenance of LTP was markedly improved by a concentration of 1.5 order lower of the antioxidant tested. The data suggest that SMe1EC2 may prove beneficial in the prevention of ischemic stroke and age-related cognitive impairment.

Acknowledgements. The study was supported by the grants VEGA 2/0048/11 and APVV-51-017905. This article is dedicated in memoriam to our dear colleague Mgr. Vladimir Snirc, PhD, who synthetized dozens of new pyridoindole derivatives of the parental drug stobadine, including the prospective compound coded SMe1EC2. The authors thank Mrs. Julia Polakova for her technical assistance.

There is no conflict of interest.

\section{References}

Barkov N. K. (1973): On the mechanism of action of carbidine. Pharmacol. Toxicol. 36, 154-157

Benes L., Stolc S. (1989): Stobadine. Drugs Future 14, 135-137

Bliss T. V., Collingridge G. L. (1993): A synaptic model of memory: Longterm potentiation in the hippocampus. Nature 361, 31-39 http://dx.doi.org/10.1038/361031a0

Brouns R., De Deyn P. P. (2009): The complexity of neurobiological processes in acute ischemic stroke. Clin. Neurol. Neurosurg. 111, 483-495 http://dx.doi.org/10.1016/j.clineuro.2009.04.001

Candelario-Jalil E. (2009): Injury and repair mechanisms in ischemic stroke: considerations for the development of novel neurotherapeutics. Curr. Opin. Investig. Drugs. 10, 644-654

Canhao P., de Mendonca A., Ribeiro J. A. (1994): 1,3-Dipropyl-8cyclopentylxantine attenuates the NMDA response to hypoxia in the rat hippocampus. Brain Res. 661, 265-273 
http://dx.doi.org/10.1016/0006-8993(94)91203-3

Cao X. J., Wang M., Chen W. H., Zhu D. M., She J. Q., Ruan D. Y. (2009): Effects of chronic administration of melatonin on spatial learning ability and long-term potentiation in leadexposed and control rats. Biomed. Environ. Sci. 22, 70-75 http://dx.doi.org/10.1016/S0895-3988(09)60025-8

Cumming T. B., Marshall R. S., Lazar R. M. (2013): Stroke, cognitive deficits and rehabilitation: still an incomplete picture. Int. J. Stroke 8, 38-45 http://dx.doi.org/10.1111/j.1747-4949.2012.00972.x

Chan P. H. (2001): ROS in signaling and damage in the ischemic brain. Cereb. Blood Flow Metab. 21, 2-14 http://dx.doi.org/10.1097/00004647-200101000-00002

Collingridge G. I., Kehl S. J., McClennan H. (1983): Ecxitatory amino acids in synaptic transmission in the Schäffer collateral-commissural pathway of the rat hippocampus. J. Physiol. (London) 334, 33-46

Fatokun A. A., Stone T. W., Smith R. A. (2008): Oxidative stress in neurodegeneration and available means of protection. Front. Biosci. 13, 3288-3311 http://dx.doi.org/10.2741/2926

Gasparova Z., Stolc S., Snirc V. (2006): In vitro physiological evidence of enhanced neuroprotective and antioxidant action of 2,3-dihydromelatonin: a melatonin analogue. Pharmacol. Res. 53, 22-27 http://dx.doi.org/10.1016/j.phrs.2005.08.004

Gasparova Z., Jariabka P., Stolc S. (2008): Effect of transient ischemia on long-term potentiation of synaptic transmission in rat hippocampal slices. Neuroendocrinol. Lett. 29, 702-705

Gasparova Z., Ondrejickova O., Gajdosikova A., Gajdosik A., Snirc V., Stolc S. (2010): Oxidative stress induced by the Fe2+/ascorbic acid system or model ischemia in vitro: effect of carvedilol and pyridoindole antioxidant SMe1EC2 in young and adult rat brain tissue. Interdisc. Toxicol. 3, 122-126 http://dx.doi.org/10.2478/v10102-010-0051-x

Gasparova Z., Snirc V., Stolc S. (2011): The new pyridoindole antioxidant SMe1EC2 and its intervention in hypoxia/hypoglycemia-induced impairment of long-term potentiation in rat hippocampus. Interdisc. Toxicol. 4, 56-61 http://dx.doi.org/10.2478/v10102-011-0011-0

Gahtan E., Auerbach J. M., Groner Y., Segal M. (1998): Reversible impairment of long-term potentiation in transgenic $\mathrm{Cu} / \mathrm{Zn}$ SOD mice. Eur. J. Neurosci. 10, 538-544 http://dx.doi.org/10.1046/j.1460-9568.1998.00058.x

Hall E. D., Braughler J. M., McCall J. M. (1992): Antioxidant effects in brain and spinal cord injury. J. Neurotrauma $\mathbf{9}$, S165-172

Hall E. D., Andrus P. K., Smith S. L., Oostveen J. A., Scherch H. M., Lutzke B. S., Raub T. J., Sawada G.A., Palmer J.R., Banitt L.S., Tustin J.S., Belonga K.L., Ayer D.E., Bundy G. L. (1996): Neuroprotective efficacy of microvascularly-localized versus brainpenetrating antioxidants. Acta Neurochir. 66, S107-113

Hofmeijer J., van Putten M. J. A. M. (2012): Ischemic cerebral damage an appraisal of synaptic failure. Stroke 43, 607-615 http://dx.doi.org/10.1161/STROKEAHA.111.632943

Horakova L., Stolc S. (1998): Antioxidant and pharmacodynamic effects of pyridoindole stobadine. Gen. Pharmacol. 30, $627-638$
http://dx.doi.org/10.1016/S0306-3623(97)00300-5

Jackson T. C., Rani A., Kumar A., Foster T. C. (2009): Regional hippocampal differences in AKT survival signaling across the lifespan: implications for CA1 vulnerability with aging. Cell Death Differ. 16, 439-448 http://dx.doi.org/10.1038/cdd.2008.171

Juranek I., Horakova L., Rackova L., Stefek M. (2010): Antioxidants in treating pathologies involving oxidative damage: an update on medicinal chemistry and biological activity of stobadine and related pyridoindoles. Curr. Med. Chem.17, 552-570 http://dx.doi.org/10.2174/092986710790416317

Juranek I., Rackova L., Stefek M. (2012): Stobadine - an indole type alternative to the phenolic antioxidant reference trolox. In: Biochemistry. (Ed. D. Ekinci), pp. 443-452, InTech, Rijeka http://dx.doi.org/10.5772/32784

Klann E. (1998): Cell-permeable scavengers of superoxide prevent long-term potentiation in hippocampal area CA1. J. Neurophysiol. 80, 452-457

Klann E., Robertson E. D., Knapp L. T., Sweatt J. D. (1998): A role for superoxide in protein kinase $\mathrm{C}$ activation and induction of long-term potentiation. J. Biol. Chem. 273, 4516-4522 http://dx.doi.org/10.1074/jbc.273.8.4516

Knapp L. T., Klann E. (2002a): Potentiation of hippocampal synaptic transmission by superoxide requires the oxidative activation of protein kinase C. J. Neurosci. 22, 674-683

Knapp L. T., Klann E. (2002b): Role of reactive oxygen species in hippocampal long-term potentiation: Contributory or inhibitory? J. Neurosci. Res. 70, 1-7 http://dx.doi.org/10.1002/jnr.10371

Larsson E., Lindvall O., Kokaia Z. (2001): Stereological assessment of vulnerability of immunocytochemically identified striatal and hippocampal neurons after global cerebral ischemia in rats. Brain Res. 913, 117-132 http://dx.doi.org/10.1016/S0006-8993(01)02762-7

Latini S., Bordoni F., Corradetti R., Pepeu G., Pedata F. (1999): Effect of A2A adenosine receptor stimulation and antagonism on synaptic depression induced by in vitro ischaemia in rat hippocampal slices. Br. J. Pharmacol. 128, 1035-1044 http://dx.doi.org/10.1038/sj.bjp.0702888

Lynch G., Larson K., Kelso S., Barrionuevo G., Schottler F. (1983): Intracellular injections of EGTA block induction of hippocampal long-term potentiation. Nature 305, 719-721 http://dx.doi.org/10.1038/305719a0

Lynch M. A. (1998): Analysis of the mechanisms underlying the age-related impairment in long-term potentiation in the rat. Rev. Neurosci. 9, 169-201 http://dx.doi.org/10.1515/REVNEURO.1998.9.3.169

Lynch M. A. (2004): Long-term potentiation and memory. Physiol. Rev. 84, 87-136 http://dx.doi.org/10.1152/physrev.00014.2003

Malenka R. C., Kauer J. A., Zucker R. S., Nicoll R. A. (1988): Postsynaptic calcium is sufficient for potentiation of hippocampal synaptic transmission. Science 242, 81-84 http://dx.doi.org/10.1126/science.2845577

Malenka R. C., Nicoll R. A. (1999): Long-term potentiation: a decade of progress? Science $285,1870-1874$ http://dx.doi.org/10.1126/science.285.5435.1870 
McGahon B. M., Martin D. S., Horrobin D. F., Lynch M. A. (1999a): Age-related changes in synaptic function: analysis of the effect of dietary supplementation with omega-3 fatty acids. Neuroscience 94, 305-314 http://dx.doi.org/10.1016/S0306-4522(99)00219-5

McGahon B. M., Martin D. S., Horrobin D. F., Lynch M. A. (1999b): Age-related changes in LTP and antioxidant defenses are reversed by a-lipoic acid-enriched diet. Neurobiol. Aging 20, 655-664 http://dx.doi.org/10.1016/S0197-4580(99)00050-0

Morris R. G. M. (2003): Long-term potentiation and memory. Philos. Trans. R. Soc. Lond. B. Biol. Sci. 358, 643-647 http://dx.doi.org/10.1098/rstb.2002.1230

Murray C. A., Lynch M. A. (1998): Dietary supplementation with vitamin $\mathrm{E}$ reverses the age-related deficits in long-term potentiation in dentate gyrus. J. Biol. Chem. 273, 12161-12168 http://dx.doi.org/10.1074/jbc.273.20.12161

Negishi H., Ikeda K., Nara Y., Yamori Y. (2001): Increased hydroxyl radicals in the hippocampus of stroke-prone spontaneously hypertensive rats during transient ischemia and recirculation. Neurosci. Lett. 306, 206-208 http://dx.doi.org/10.1016/S0304-3940(01)01893-6

O’Donnell E., Lynch M. A. (1998): Dietary antioxidant supplementation reverses age-related neuronal changes. Neurobiol. Aging 19, 461-467 http://dx.doi.org/10.1016/S0197-4580(98)00082-7

Olney J.W. (1994): New mechanisms of excitatory transmitter neurotoxicity. J. Neural. Transm. Suppl. 43, 47-51

Pellmar T. C., Roney D., Lepinski D. (1992): Role of glutatione in repair of free radical damage in hippocampus in vitro. Brain Res. 583, 194-200 http://dx.doi.org/10.1016/S0006-8993(10)80024-1

Pulsinelli W. A., Brierley J. B. (1979): A new model of bilateral hemispheric ischemia in the unanesthetized rat. Stroke 10, 267-272 http://dx.doi.org/10.1161/01.STR.10.3.267

Reiter R. J., Tan D. X., Manchester L. C., Tamura H. (2007): Melatonin defeats neurally-derived free radicals and reduces the associated neuromorphological and neurobehavioral damage. J. Physiol. Pharmacol. (Suppl. 6) 58, 5-22

Reiter R. J., Tan D. X., Jou M. J., Korkmaz A., Manchester L. C. Paredes S. D. (2008): Biogenicamines in the reduction of oxidative stress: melatonin and its metabolites. Neuroendocrinol. Lett. 29, 391-398

Robertson E. D., English J. D., Sweatt J. D. (1996): A biochemist's view of long-term potentiation. Learn. Mem. 3, 1-24 http://dx.doi.org/10.1101/lm.3.1.1

Saito A., Maier C. M., Narasimhan P., Nishi T., Song Y. S., Yu F., Liu J., Lee Y. S., Nito C., Kamada H., Dodd R. L., Hsieh L. B., Hassid B., Kim E. E., González M., Chan P. H. (2005): Oxidative stress and neuronal death/survival signaling in cerebral ischaemia. Mol. Neurobiol. 31, 105-116

http://dx.doi.org/10.1385/MN:31:1-3:105

Sanderson T. H., Reynolds C. A., Kumar R., Przyklenk K., Huttemann M. (2013): Molecular mechanisms of ischemia-reperfusion injury in brain: Pivotal role of the mitochondrial membrane potential in ROS generation. Mol. Neurobiol. 47, 9-23 http://dx.doi.org/10.1007/s12035-012-8344-z
Stolc S., Bauer V., Benes L., Tichy M. (1983): Medicine with antiarrhythmic and antihypoxic activity and its method of preparation. Patents: CS 229 067, SWED. 8204693-9, BELG. 894148, SWISS 651 754, BRD P-3231088, SPAIN 553 017, Jap. 1514040

Stolc S., Snirc V., Majekova M., Gasparova Z., Gajdosikova A., Stvrtina S. (2006): Development of the new group of indolederived neuroprotective drugs affecting oxidative stress. Cell. Mol. Neurobiol. 26, 1495-1504 http://dx.doi.org/10.1007/s10571-006-9037-9

Stolc S., Povazanec F., Bauer V., Majekova M., Wilcox A. L, Snirc V., Rackova L., Sotnikova R., Stefek M., Gasparova Z., Gajdosikova A., Mihalova D., Alfoldi J. (2010): Pyridoindole derivatives with antioxidant properties; their synthesis and use in therapeutic practice. Slovak Patent No. 287506 (in Slovak)

Stolc S., Snirc V., Gajdosikova A., Gajdosik A., Gasparova Z., Ondrejickova O., Sotnikova R., Viola A, Rapta P. (2011): Pyridoindols with antioxidant and neuroprotective actions: A review. In: New Frontiers in Molecular Mechanisms in Neurological and Psychiatric Disorders. (Eds. E. Babusikova, D. Dobrota and J. Lehotsky), Vol. 1, pp. 316-341, Department of Medical Biochemistry, Comenius Universtity in Bratislava, Jessenius Faculty of Medicine in Martin,

Sugawara T., Chan P. H. (2003): Reactive oxygen radicals and pathogenesis of neuronal death after cerebral ischemia. Antiox. Redox. Signal. 5, 597-607

Thiels E., Urban N. N., Gonzales-Burgos G. R., Kanterewitz B. I., Barrionuevo G., Chu C. T., Oury T. D., Klann E. (2000): Impairment of long-term potentiation and associative memory in mice that overexpress extracellular superoxide dismutase. J. Neurosci. 20, 7631-7639

Ujhazy E., Dubovicky M., Ponechalova V., Navarova J., Brucknerova J., Snirc V., Mach M. (2008): Prenatal developmental toxicity study of the pyridolindole antioxidant SMe1EC2 in rats. Neuroendocrinol. Lett. 29, 639-643

Vlkolinsky R., Stolc S. (1999): Effect of stobadine, melatonin, and other antioxidants on hypoxia/re-oxygenation-induced synaptic failure in rat hippocampal slices. Brain Res. 850, 118-126 http://dx.doi.org/10.1016/S0006-8993(99)02110-1

Wang H. L., Chen X. T., Yin S. T., Liu J., Tang M. L., Wu C. Y., Ruan D. Y. (2008): Opposite effects of $\alpha$-lipoic acid on antioxidation and long-term potentiation in control and chronically lead-exposed rats. Naunyn. Schmied. Arch. Pharmacol. 378, 303-310 http://dx.doi.org/10.1007/s00210-008-0307-6

Zhang Y. B., Kan M. Y., Yang Z. H., Ding W. L., Yi J., Chen H. Z., Lu Y. (2009): Neuroprotective effect of N-stearoyltyrosine on transient global cerebral ischemia in gerbils. Brain Res. 1287, $146-156$ http://dx.doi.org/10.1016/j.brainres.2009.06.070

Zhu L., Fratiglioni L., Guo Z., Aguero-Torres H., Winblad B., Viitanen M. (1998): Association of stroke with dementia, cognitive impairment, and functional disability in the very old. A population-based study. Stroke 29, 2094-2099 http://dx.doi.org/10.1161/01.STR.29.10.2094

Received: March 28, 2013

Final version accepted: July 29, 2013 